\title{
Essence, modality, and intrinsicality
}

\author{
Gaétan Bovey ${ }^{1}$ (D) \\ Received: 30 April 2019 / Accepted: 13 January 2020 / Published online: 12 March 2020 \\ (c) The Author(s) 2020
}

\begin{abstract}
Kit Fine (Philos Perspect 8:1-16, 1994) famously objected against the idea that essence can be successfully analyzed in terms of de re necessity. In response, I want to explore a novel, interesting, but controversial modal account of essence in terms of intrinsicality and grounding. In the first section, I will single out two theoretical requirements that any essentialist theory should meet — the essentialist desideratum and the essentialist challenge-in order to clarify Fine's objections. In the second section, I will assess Denby's improved modal account, which appeals to the notion of intrinsicality, and argue that it is untenable. In the third section, I will explain how, when combined with a modal-existential criterion, a hyperintensional account of intrinsicality-in the same vein as Bader (J Philos 110(10):525-563, 2013) and Rosen (in: Hale and Hoffman (eds) Modality: Metaphysics, logic, and epistemology, Oxford, OUP, 2010)—can help successfully address Fine's counterexamples. In the fourth section, I will evaluate how this novel analysis of essence stands with respect to sortal, origin, and natural kinds essentialism and discuss potential objections and difficulties.
\end{abstract}

Keywords Essence $\cdot$ Essentialism $\cdot$ Modality $\cdot$ Intrinsicality $\cdot$ Grounding $\cdot$ Parthood

\section{Introduction: the essentialist desideratum and the essentialist challenge}

In his influential paper Essence and Modality (1994) Kit Fine argues that, as they stand, modal analyses of essence-both the conditional and the unconditional variants (Correia 2007)_bring about controversial and counterintuitive results. In order to see why, let us consider the conditional analysis for the present discussion:

CMA: $x$ is essentially $\mathrm{F}=$ def. necessarily, if $x$ exists, then $x$ is $\mathrm{F}$.

Gaétan Bovey

gaetan.bovey@uni-tuebingen.de

1 Department of Philosophy, University of Tübingen, Bursagasse 1, 72070 Tübingen, Germany 
In short, what (CMA) states is that the essential properties of $x$ just are-or, equivalently, are nothing over and above-the properties that $x$ necessarily instantiates if $x$ exists.

Yet according to Fine, we should distinguish between the necessary and the essential properties of entities. He claims that these two categories of properties should not be conflated with one another, because they are not coextensive (and not even coincidentally). I think we can best understand Fine's reasons for arguing for this by focusing on how he characterizes the theoretical purpose of essentialism. His rationale is that, in the same way that metaphysical grounding goes hand-in-hand with a specific kind of questions — namely, 'why-questions' — essentialism is closely associated with 'what-questions'.1 Quite obviously, questions such as 'what time is it?' or 'what is the capital of India?' are not of theoretical interest here. Rather, the metaphysically significant what-questions are concerned with the identity of things, with what they are. So when metaphysicians ask 'what is $x$ ?'-or, equivalently, 'what is the nature of $x$ ? - their theory of essence should (at least partially) provide an informative and relevant answer about the identity of $x$. To put it another way, the fundamental purpose of essentialist claims is to accurately describe the nature of the things they are about. A theory of essence that succeeds in achieving such a task meets what I label the essentialist desideratum. I will not challenge Fine with respect to these observations, as I think he is right.

According to Fine, the problem with (CMA) is that although it meets the essentialist desideratum in most circumstances, it nonetheless over-generates essential properties. To give a paradigmatic example, (CMA) complies with our intuitions by qualifying being human as an essential property of Socrates, for we tend to think that it is necessary for Socrates to be human if he exists. Arguably then, this result yields a partial and correct answer to the question 'what is Socrates?', for it states something relevant about Socrates's nature. ${ }^{2}$ But on the other hand, (CMA) has the consequence of wrongly ascribing being a member of \{Socrates\}, being distinct from the Eiffel Tower, being such that $\varphi$ (where $\varphi$ is a necessary truth), and existing as essential properties of Socrates. ${ }^{3}$ This is so because as a matter of necessity, Socrates is such that if he exists, he instantiates each of the these properties. Yet, as Fine correctly observes, the claims that Socrates is necessarily distinct from the Eiffel Tower, or that he is necessarily the sole member of \{Socrates\} (or, for that matter, the member of each set to which he belongs) if he exists do not describe in any relevant manner his innermost nature. As Fine puts it, "[s]trange as the literature on personal identity may be, it has never been suggested that in order to understand the nature of a person one must know to which sets he belongs" (1994, p. 5). Fine is thereby perfectly entitled to conclude that (CMA) fails badly to meet the essentialist desideratum with respect to these specific counterexamples.

A natural reaction to Fine's objections consists in arguing that essential properties must satisfy further conditions. But with this kind of strategy, one has to make sure

\footnotetext{
${ }^{1}$ I borrow the terminology of Cowling (2013).

2 Though see Mackie (2006) for arguments against such sortal claims.

${ }^{3}$ Although Fine is usually credited for some of these arguments, they can be traced back to the work of Dunn (1990b).
} 
that these latter are neither ad hoc nor too restrictive. This takes us to Fine's most difficult point to address. Consider again Socrates and his singleton: a necessary and sufficient condition for the existence of a given set is that its members exist. Thus, as a matter of necessity, \{Socrates\} exists just in case Socrates exists. Furthermore, it is necessary that if both \{Socrates and Socrates exist, then Socrates is a member of $\{$ Socrates $\}$ and $\{$ Socrates $\}$ contains Socrates. Consequently: it is necessary that if \{Socrates\} exists, then Socrates belongs to \{Socrates\}, and that if Socrates exists, then Socrates belongs to \{Socrates\}.

It follows from (CMA) that (1) it is essential to Socrates to be a member of \{Socrates\}, and (2) it is essential to \{Socrates\} to contain Socrates. And as explained before, (1) is false in light of the essentialist desideratum. So far so good. But what about (2)? As Fine puts it, "can we not recognize a sense of nature, or of "what an object is', according to which it lies in the nature of the singleton to have Socrates as a member [...]?" (1994, p. 5, emphasis mine). Indeed, if there is but one property that should count as essential to \{Socrates\}, it is precisely containing Socrates. For given that sets are characterized (or 'defined') by their members, the nature of \{Socrates is (at least partly) expressible by the claim that $\{$ Socrates $\}$ possesses Socrates as a member. In fact, this is just what it is to be that abstract entity. So (CMA) provides the correct answer with respect to (2), but the wrong answer with respect to (1). Hence, a modal reductionist convinced by Fine's arguments should typically provide an analysis according to which (1) is false and (2) is true. ${ }^{4}$

We now have within our hands the required theoretical elements to identify the essentialist challenge, which consists in making sense of the intuitive asymmetric relation of essentiality that holds between some particular interconnected entities. For the present discussion, my main focus will be on the relational properties containing Socrates and being a member of \{Socrates\}-in order to convey the asymmetric relation that holds between Socrates and \{Socrates\}. Specifically, I want to evaluate to what extent the essentialist challenge can be met-i.e., what it takes for a view to accommodate the truth of (2) and the falsity of (1). I will come to Fine's other counterexamples later in the paper.

So how can modal reductionists successfully meet the essentialist challenge? As long as the essentialist desideratum is taken seriously, one cannot just ignore Fine's insightful counterexamples and defend essentialism on satisfactory grounds. Fortunately, there are at least two interesting options available: either (a) we can try to improve (CMA) with an additional condition (or more than one additional condition) that essential properties must satisfy, or (b) we can just abandon the project of reducing essence to necessity and opt for a different picture of essentialism instead. ${ }^{5}$

Here is, in substance, what Fine has to say about (a) and its viability:

\footnotetext{
4 As an anonymous referee has pointed out to me, there is a serious concern in the literature that surrounds Fine's counterexamples and the responses to them. For instance, a convinced nominalist will hardly find Fine's counterexamples involving Socrates and \{Socrates\} convincing. Others, such as Gorman (2005, p. 278), argue that Fine's counterexamples are too artificial. For the present study, Fine's objections are taken seriously.

5 Other options include (but are not limited to) endorsing skepticism vis-à-vis essentialism or defending specific metaphysical frameworks such as Brogaard and Salerno (2007), Correia (2007) and Zalta (2006). For a discussion of these views see Torza (2015).
} 
But might there not be some other, perhaps quite different, version of the modal criterion which is not subject to these difficulties? Although it is hard to be definitive on such a matter, I think it can plausibly be made out that no such alternative account is to [be] found. For it seems to be possible to agree on all of the modal facts and yet disagree on the essentialist facts. But if any modal criterion of essence were correct, such a situation would be impossible. [...] [T] he subject should not be taken to be constituted, either in principle or practice, by its claims of necessity (Fine 1994, p 7, emphasis mine).

According to Fine then, modal analyses cannot be tuned in such a way as to reliably capture the nature of things, to single out their essential properties. In a word, he thinks that both the essentialist desideratum and the essentialist challenge cannot be met as long as one is entangled with modal notions. Although it might be obvious, let me stress that Fine's conclusion holds as long as what he means by a 'modal criterion of essence' is a criterion which reduces essence to de re necessity simpliciter. That is, by themselves, Fine's insightful observations together with his conclusion just quoted above are not sufficient to establish that it is impossible to defend a hybrid modal analysis of essence that satisfies both the essentialist desideratum and the essentialist challenge.

Be that as it may, it is not among Fine's plans to pursue an in-depth investigation of this matter as he champions (b) and argues, inter alia, that necessity reduces to essence and not the other way around. ${ }^{6}$ Finean essentialism is attractive in many respects, such as, for instance, the fact that it provides a plausible account of what the source of necessity is. I shall not evaluate Fine's account any further, as this would take us far beyond the scope of the present paper. The following discussion will be focused on (a) instead. Given Fine's insightful observations, let us now investigate to what extent one can provide a refined and satisfactory modal analysis of essence.

\section{Essence and intrinsicality: a critical assessment of Denby's improved modal account}

Among the authors who have opted for the (a)-strategy, Cowling (2013) and Wildman (2013) argue that an essential property is not only a property that entities cannot fail to instantiate in case they exist, but also-following Lewis (1986) - a sparse property. This idea has been severely_and, in my view, convincingly-criticized by Skiles (2015). Other sophisticated modal accounts include notably Della Rocca (1996) and Gorman (2005), to which Wildman (2016) is opposed. Finally, Livingstone-Banks (2017) has recently put forward an interesting strategy to address Fine's counterexamples, but I will not discuss his view here. I will therefore leave such an inquiry for another time.

The main purpose of my study is to argue in favor of the idea that, in addition to the modal-existential condition of (CMA), essential properties must satisfy a criterion of intrinsicality. As a matter of fact, David Denby has put forward this idea in his Essence

\footnotetext{
6 The thesis according to which metaphysical modality reduces to essence has recently been challenged by, inter alia, Romero (2018), Teitel (2017), and Wildman (2018).
} 
and Intrinsicality (2014). However, the theoretical outcomes of his analysis have not yet been fully appreciated or systematically discussed in the literature. Thus, I shall first evaluate to what extent Denby's modal account is satisfactory for our present concerns. Once this is done, I will argue in favor of a different analysis of intrinsic properties which is not only desirable per se, but which can also straightforwardly meet both the essentialist desideratum and the essentialist challenge. Ultimately, I hope that the following exploratory discussion will clarify some important points to bear in mind if one favors (a) over (b).

To begin with, the task of motivating an additional criterion of intrinsicality to single out essential properties should not be overlooked. Intuitively, an intrinsic property of $x$ is a property instantiated by $x$ solely in virtue of how $x$ is in itself, independently of anything external (such as a condition, factor, entity, etc.) to $x$. On the other hand, an extrinsic property of $x$ is a property instantiated by $x$ in virtue of something being external from $x .^{7}$ So if the essentialist desideratum is to be met, the notion of instrinsicality can help precisely by circumscribing the scope of modal analyses so as to focus exclusively on the nature of entities, on what makes them what they are and in virtue of which they are how they are. In other words, given that modal terms are required but not sufficient to meet the essentialist desideratum, the purpose of the notion of intrinsicality is to fill this theoretical gap so as to obtain both a necessary and sufficient condition to accurately single out essential properties. ${ }^{8}$ Finally, let me stress that improving (CMA) with a condition of intrinsicality should not be seen as an ad hoc strategy - quite the opposite-as it takes us closer to the innermost nature of the entities considered. Both Denby and I agree on this important point.

In his paper, it is clear that Denby intends to address the essentialist challenge when he claims "that essential properties are intrinsic and that this permits a modal analysis of essence that is immune to the sort of objections raised by Fine" (2014, p. 89). So as a first step, let us focus on how Denby characterizes the intrinsic/extrinsic properties distinction:

I: "Roughly, a property is intrinsic iff its instantiation is insensitive to the state or nature of anything other than its instances; otherwise, it is extrinsic" (ibid., p. 91).

As far as Fine's counterexamples are concerned, Denby does not develop his views on intrinsicality any further. He briefly mentions that one can use Lewis's (1986) account of intrinsic properties as a useful test, but he does not rely on it in his discussion on essentialism. Denby's main point, as I understand it, is to give an intuitive gloss of intrinsicality and to demonstrate that this is sufficient to address the problems faced by (CMA). I will therefore follow what Denby says in the text closely so as to avoid any confusion about — or misinterpretation of-his view.

Denby naturally improves (CMA) as follow:

\footnotetext{
7 As Dunn also explains, "[e]pistemologically, an intrinsic property would be a property that one could determine by inspection of the object itself - in particular, for a physical object, one would not have to look outside of its region of spacetime" (Dunn 1990a, p. 178).

8 Interestingly, Forbes explains that "if the fundamental asymmetry [between Socrates and \{Socrates\}] is intrinsic/extrinsic, we need a further argument that all essential properties must be intrinsic before this difference can overturn the modal definition" (Forbes 2001, footnote 6).
} 
CMAI: $x$ is essentially $\mathrm{F}=\operatorname{def}$. $\mathrm{F}$ is intrinsic and necessarily, if $x$ exists, then $x$ is $\mathrm{F}^{9}$

According to Denby, (CMAI) can accommodate each of Fine's counterexamples. If this is true, then so much the better for modal reductionists of essence! Denby's explanations boil down to this:

T: "By excluding extrinsic properties, [(CMAI)] disqualifies properties that involve things other than their instances from being essential. It thereby avoids Fine-style counterexamples, all of which do drag in other things—primes, argument forms, the Eiffel Tower, specks of dust, etc." (Denby 2014, p. 92).

If we follow strictly Denby's terminology in (I), Fine's counterexamples are avoided because they are sensitive to the state/nature of things other than their instances. ${ }^{10}$ To that extent then, (CMAI) is a successful analysis of essence. However, there is a disastrous consequence for (CMAI): Denby argues that containing Socrates is an extrinsic_and therefore not an essential-property of \{Socrates\}:

- The extrinsicality and essentiality problem (EEP): Whether a set contains Socrates doesn't have anything to do with its intrinsic properties, whatever they might be. How could a set-or anything else-intrinsically involve something distinct from itself? So sets have some extrinsic properties essentially, and [(CMAI)] is false. Mutatis mutandis for grounded entities generally: if $\mathrm{x}$ is grounded in $\mathrm{y}$, then being grounded in $y$ is an extrinsic property that is essential to $\mathrm{x}$ (ibid., pp. 93-94). ${ }^{11}$

In his explanations, Denby starts by posing a fundamental challenge, namely 'how could anything intrinsically involve something distinct from itself?'. ${ }^{12}$ The crucial point in this question — as well as in (T) — is that what Denby means by 'something distinct' or 'things other than their instances' is, respectively, 'something wholly distinct' and 'things being wholly distinct from their instances'. I will return to this point in Sect. 3. Moreover, Denby's explanations are not—-terminologically speaking-strictly faithful to (I), but the idea is that containing Socrates is extrinsic because its instantiation $i s$ sensitive to the state/nature of a thing other than the instance of the singleton, namely Socrates. Be that as it may, this conclusion is at odds with Fine's insight that containing Socrates is an essential property of $\{$ Socrates $\}$.

In order to address (EEP), Denby argues that we should deny that

sets have their members essentially. [...]. [Because] neither set theory nor any of its theoretical deployments seems to require that \{Socrates\} have contains

\footnotetext{
9 Denby's exact formulation is ' $\mathrm{x}$ has $\mathrm{F}$ essentially iff $\mathrm{x}$ has $\mathrm{F}$ at every world and $\mathrm{F}$ is intrinsic', but this will not substantially affect the present discussion.

10 However, let me stress that, as opposed to what he thinks, Denby should not rely on Lewis's (1986) duplication account as a 'useful test' for his explanations, because it classifies necessary-properties like being such that there are numbers as intrinsic. For a discussion see Eddon (2011).

11 I would like to briefly say that there is something specious in (EEP). Denby asks 'How could a set intrinsically involve something distinct from itself?' This is a misguided question. It is not the set that is responsible its involving something distinct from itself (sets do not determine their relation with their members). Rather, it is the characteristic feature of the property - in this case containing Socrates - that determines whether the set possesses its member intrinsically or extrinsically.

12 Thanks to T. Wilsch for pushing this point.
} 
Socrates essentially. They require only that, for any things, there be a unique set having exactly those things as members, and presumably that this be the case at every world. [...] At every world, Socrates' dog belongs to Socrates, but it is not of the essence of any dog to belong to Socrates; it is just that if they part ways, the dog no longer qualifies as his (ibid., p. 94).

I disagree. First, it is not the task of set theory-let alone of any of its axioms or principles - to define which properties are essential to abstract and concrete entities such as sets and their members. Set theory is, in the first place, concerned with the mathematical science of the infinite and the foundations of mathematics (cf. Bagaria 2017). Rather, it is the metaphysician's task to answer specific questions of essence as well as to take a position on such matters. Denby's answer to (EEP) is equivalent to a situation in which a physicist would say that endurantism is false because spacetime theories do not require that things exist in time in such a fashion. Second, the relational property belonging to $x$ has a different metaphysical implication from what the relational property containing $x$ has. This is notably reflected in the asymmetry between Socrates and \{Socrates\} that Fine has pointed out in his objections to (CMA). In sum, although he acknowledges that it is not essential for Socrates to be a member of $\{$ Socrates $\}$, Denby maintains that containing Socrates is not essential to \{Socrates given his views on intrinsicality. He thus gives no credit to the 'sense of nature' put forward by Fine. (Given this result, it would maybe have been wise to abandon (I) in favor of a more detailed analysis of intrinsicality.)

At this stage, let me reinforce Fine's insights with the following observation made by Lowe:

Consider the [...] set of planets whose orbits lie within that of Jupiter. What kind of thing is that? Well, of course, it is a set, and as such an abstract entity that depends essentially for its existence and identity on the things that are its members - namely, Mercury, Venus, Earth, and Mars. Part of what it is to be a set is to be something that depends in these ways upon certain other things- the things that are its members. Someone who did not grasp that fact would not understand what a set is (Lowe 2008, p. 37).

Here, we have a straightforward explanation of why a set contains its members essentially: the existence and the identity of a set depend upon its members. I think that we should side with Fine and Lowe for whom it is not only counterintuitive but also wrong that singletons and sets do not contain their members essentially. ${ }^{13}$ And it is surprising to read what Denby argues with respect to this point: when we say that an entity, $x$, is essentially $\mathrm{F}$, "we don't just mean that $\mathrm{x}$ couldn't survive the loss of F. We usually mean that $x$ couldn't survive any variation in the kind of property to which F belongs" (2014, p. 89). So let me ask: "could \{Socrates\} survive the loss of the property containing Socrates?' and 'could \{Socrates\} survive any variation in the kind of property (viz., containing a member) to which containing Socrates belongs?', certainly not. For $\{$ Socrates $\}$ can neither exist without instantiating the property con-

\footnotetext{
13 See also Forbes: "[T]he members of a set are its essence, in the sense that if certain objects are the members of a set $x$ in some world, then the property of having exactly those objects as members is an essence of $x "(1985$, p. 98).
} 
taining Socrates, nor be what it is if it fails to possess any member at all (in this case it would be the null-set, but obviously $\varnothing \neq$ \{Socrates $\}$ ) or if one were inclined to produce a property-variation like containing $x$, where $x \neq$ Socrates.

Furthermore, it is clear that in Denby's above example, the existence of the dog does not depend upon the existence of Socrates, while the existence of \{Socrates\} does depend entirely upon Socrates's existence: had this latter failed to exist, the singleton would not exist. Fine makes this point very clear when he explains that "one object depends upon another [...] if its essence prevents it from existing without the other object" (Fine 1994, p. 2). Be that as it may, Denby gives the following additional reasons to not consider containing Socrates as an essential property of \{Socrates\}:

There are epistemic and semantic asymmetries between sets and their members: our grasp of and reference to \{Socrates\} must go via Socrates, but not vice versa. Perhaps that is why it seems natural to say that sets have their members essentially: their membership provides our only access to them. However, a metaphysical asymmetry remains elusive. Sets are posited as abstract correlates of things - one for each collection of things. But neither their abstractness nor the fact that they are posited shows that $\{$ Socrates $\}$ contains Socrates essentially. And the correlation is symmetrical: sets exist iff their members do. I conclude that even if properties like contains Socrates are extrinsic, they do not force us to abandon [(CMAI)] because they don't seem to be essential to their instances. Mutatis mutandis, for the defining properties of other grounded entities (Denby 2014, p. 96).

Why should we think that asymmetries involving the notion of essence are somehow obscure or ungraspable? As Denby correctly observes, neither the abstractness of sets nor the fact that they are posited show that they contain their members essentially. However, the explanation does not simply end here, because it is the fact that the existence of sets depends upon the existence of their members that explains why sets have their members essentially. ${ }^{14}$ In other words, as long as we understand that Socrates's existence does not depend on \{Socrates\}'s, and that \{Socrates\}'s existence does depend upon Socrates's, I do not see what (if anything) is elusive about such a metaphysical asymmetry. ${ }^{15}$ At least, I shall say, it is no more elusive than the asymmetry that holds between grounding and grounded facts, realism about integers versus realism about natural numbers (cf. Fine 2009), or even the fact that Socrates's existence depends on the existence of his parents. Such metaphysical asymmetries are needed as constraints on explanatory theories about the notions in question, and it is Fine's most difficult point for modal reductionists to address-i.e., the essentialist challenge. Moreover, Denby's claim that 'Socrates exists iff \{Socrates\} exists' (which I take to be true) does not entail, in and of itself, that there is a symmetric relation of dependence between

\footnotetext{
14 See Lowe's quote above.

15 As Schaffer puts it, "given that Socrates exists, his singleton \{Socrates\} must exist. And conversely, given that $\{$ Socrates $\}$ exists, there must be Socrates. Yet-given the iterative conception, on which sets are founded on their members-there is an asymmetry. \{Socrates \} exists in virtue of Socrates and not vice versa. Sets depend on their members [...]. One who noted the existence of Socrates, the truth of $<$ Socrates exists $>$, and the existence of \{Socrates\}, but missed the asymmetric dependence relations among them, would have missed an aspect of the world" (2010, p. 35).
} 
these two entities. Rather, what the equivalence states is that if we admit set members in our ontology, we ipso facto have to admit the sets to which they belong in our ontology, and vice versa. ${ }^{16}$

Finally, Denby makes a controversial point regarding haecceities (e.g., properties like being Socrates). At the lights of (I), Denby argues that, as opposed to what one might think, "being Socrates is not intrinsic [...] because it is 'uniquenessentailing' - if $x$ has it, everything else lacks it - and so implicitly it does involve other things after all" (2014, p. 97). So according to Denby, haecceities are extrinsic properties and they are therefore not essential to their bearers. While he acknowledges that a re-characterization of (CMAI) or intrinsic properties might be solutions to accommodate the intuition that haecceities are essential, Denby argues that "we should just bite the bullet and deny that they really are" (ibid., p. 98). I think that Denby gets things wrong when it comes to haecceities, for indeed such properties are a paradigmatic example of properties that are both intrinsic and essential to their bearers. As Yablo explains, a "theory of intrinsicness should not predict right out of the starting gate that there is no such thing as intrinsic identity" (1999, p. 487). (I will return to haecceities in Sect. 4.)

Be that as it may, I will not discuss Denby's account any further: one can be convinced by (CMAI), but I maintain that Denby dismisses the essentialist challenge on unsatisfactory grounds. More precisely, we should not take Denby's account as a solution to Fine's counterexamples in its own right, but rather as a substantial argument in favor of the idea that neither containing Socrates nor being a member of \{Socrates\} are essential properties of \{Socrates\} and Socrates respectively. But to paraphrase Fine, 'strange as the literature on personal identity may be, it has never been suggested that one can understand the nature of a set without taking into account which are its members.'

At this point, it is worth stressing that (CMA) and (CMAI) can be contrasted as follows: contra Fine, convinced proponents of (CMA)—such as Wildman (2013)—deny that there is an asymmetry between Socrates and \{Socrates\}, for they argue that it is as much essential for Socrates to be a member of \{Socrates\} as it is essential for \{Socrates\} to contain Socrates. ${ }^{17}$ Proponents of (CMAI), on the other hand, also deny that there is an asymmetry, but argue — contra Fine and friends of (CMA) — that it is neither essential for Socrates to be a member of \{Socrates\} nor essential for \{Socrates\} to contain its sole member. ${ }^{18}$ Both views, as they stand, are unable to meet the essentialist challenge and thereby fail to meet the essentialist desideratum. ${ }^{19}$ In brief, by dismissing the essentialist desideratum's significance, one has to give sub-

\footnotetext{
16 Though see Rayo (2015) and Rosen (2006) who both explore an interesting view according to which there are worlds where both Socrates and \{Socrates\} exists and at the same time worlds where Socrates exists but \{Socrates\} does not. As N. Wildman has pointed out to me, if such a view is sustainable, we can likely just go back to the original conditional modal definition. This deserves further consideration.

17 I think that if one is willing to defend this position, one also has to defend the position that Socrates's existence depends on the existence of its singleton.

18 Note that this is also arguably true of Cowling (2013).

19 This is so because one cannot properly answer to the questions 'what is Socrates?' and 'what is \{Socrates\}?' by saying that the former essentially belongs to \{Socrates\}, and that the latter does not contain Socrates essentially.
} 
stantial arguments to explain why Socrates is essentially a member of \{Socrates $\}$ or why $\{$ Socrates $\}$ does not essentially contain Socrates. Denby's attempt to defend this latter claim is inconclusive.

The important lesson to draw from our discussion so far is that the success of modifying (CMA) with a criterion of intrinsicality depends greatly upon the criterion itself. Ideally then, our commitment towards the extrinsic/intrinsic properties distinction should not only be as uncontroversial as possible per se, but also fine-grained enough to meet the essentialist challenge. So by rejecting (CMAI), it is not my intention to argue that any other criterion of intrinsicality cannot be used for our purposes, nor is it to say that Denby's characterization should be abandoned because it fails in this particular context. Rather, what I have aimed to show is that if we are inclined to adopt a criterion of intrinsicality, then, as long as we are concerned with the essentialist challenge, we ought to refrain from endorsing Denby's. Let us now turn towards what I consider a more promising characterization of intrinsic properties, and see why-as I shall argue-it provides better results than (I) when combined with a modal-existential criterion.

\section{Towards a novel analysis of essence in terms of modality and intrinsicality}

The characterization of intrinsic properties I am about to defend draws strongly from Rosen's analysis formulated in terms of grounding:

RI: " $\mathrm{F}$ is an intrinsic property iff, as a matter of necessity, for all $\mathrm{x}$ : If $\mathrm{x}$ is $\mathrm{F}$ in virtue of $\varphi(\mathrm{y})$ - where $\varphi(\mathrm{y})$ is a fact containing $\mathrm{y}$ as a constituent-then $\mathrm{y}$ is part of $\mathrm{x}$; and If $\mathrm{x}$ is not-F in virtue of $\varphi(\mathrm{y})$, then $\mathrm{y}$ is part of $\mathrm{x}$ " (Rosen 2010, p. 112).

I will not endorse Rosen's account as it stands. One of the main reasons being that (RI) is a characterization of a global notion of intrinsic properties. As such, (RI) is meant to determine whether a property is intrinsic tout court-i.e., if a property F satisfies (RI), then F is intrinsic to all its bearers. (Note that this is how Denby characterizes intrinsic properties.) This approach to intrinsicality is controversial, because just as one can safely assume that the essential character of a property, F, does not lie in the nature of $\mathrm{F}$ itself but is rather relative to which thing instantiates $\mathrm{F}$, there is arguably a similar form of relativeness holding between $\mathrm{F}$, a bearer of $\mathrm{F}$, and the notion of intrinsicality. In fact, some properties are possessed intrinsically by some objects and extrinsically by some others. For instance, the roundness of a hole, $h$, is arguably not intrinsic to $h$ given that such a shape is (partly) determined by what surrounds $h$ (Allen 2016, p. 115). On the other hand, the roundness of a spacetime region $s$ is arguably intrinsic to $s$. To give another example, it can be safely assumed that being such that there is a proton is intrinsic to each and every proton, but not intrinsic to non-protons such as you and me. A characterization of global intrinsicality cannot make sense of such distinctions, and this constitutes a direct motivation to start with a local notion which aims to capture what it takes for a property to be intrinsic to an entity. ${ }^{20}$ In order to

\footnotetext{
20 See Bader $(2013, \S 5.3)$ for detailed explanations of why the notion of local intrinsicality is more basic than the global one. See also Plate $(2018, \S 12)$ for a discussion on local intrinsicality.
} 
achieve this, I will retain the core ideas behind (RI) (grounding and parthood), but abandon the universal quantifier, the necessity clause, as well as the second conjunct of (RI). This will not substantially affect the main discussion, and I will flag potential difficulties as I proceed to the next section.

By making these modifications to (RI), we arrive at the following characterization of local intrinsicality:

G: $\mathrm{F}$ is intrinsic to $x=$ def. $x$ is $\mathrm{F}$, and for all $y$, if $x$ is $\mathrm{F}$ in virtue of $\varphi(y)$-where $\varphi(y)$ is a fact containing $y$ as a constituent-then $y$ is a part of $x$.

As a first important remark, I will not try to define what it is for a property to be extrinsic to an entity here. Needless to say that if a property, $\mathrm{F}$, possessed by a thing, $x$, does not satisfy (G), F will not be intrinsic to $x .^{21}$ Second, (G) appeals to the relation of grounding, which I will consider as a primitive notion in what follows. ${ }^{22}$ Third and most importantly, the notion of parthood involved in (G) is not to be construed in its usual and strict mereological sense, but rather according to Fine's part-whole pluralism (2010). In substance, the idea is that in addition to the familiar relation of parthood found in classical mereology, there are other kinds of parthood relations such as set-membership, fact-constituency, as well as the relation between a sequence and its members (to name only a few). This means, inter alia, that the members of a given set, $S$, will be considered as parts of $S .{ }^{23}$ As Bader notes, part-whole pluralism "allows [our] proposed theory of intrinsicality to be applicable to entities other than material objects such as sets, structural universals, facts, and so on" (2013, p. 28, footnote 39). This is how it should be because the notion of intrinsicality should apply to different categories of entities without discrimination ab initio. Construed as such, the general notion of parthood involved in (G) supports this theoretical purpose. In what follows, I will use the label '*part' to refer to the notion of parthood invoked by Fine (which includes the mereological notion of parthood, set-membership, etc.) in order to avoid any confusion. I will discuss some potential objections and difficulties in Sect. 4.

Our main task is to examine how $(\mathbf{G})$ can help us address the essentialist challenge. Let me modify (CMA) as follow:

CMAG: $x$ is essentially $\mathrm{F}=$ def. $\mathrm{F}$ is intrinsic to $x$ as characterized by $(\mathbf{G})$, and necessarily, if $x$ exists, then $x$ is $\mathrm{F}$.

To start our investigation, is being a member of $\{$ Socrates\} an essential property of Socrates? No, because with respect to Socrates, this property does not satisfy (G).

\footnotetext{
21 The notion of being extrinsic to $x$ is not defined as the mere negation of (G). Here, I set aside specific cases where a property can be possessed both intrinsically and extrinsically by the same entity, such as, for instance, being such that there is a proton. (It is not clear whether a given proton in our universe possesses two different properties in this case or not.)

22 Though see, inter alia, Correia and Skiles (2017), Rosen (2010), Schaffer (2016), and Wilsch (2015) who propose analyzing grounding in further terms.

23 The way in which an object is a part of a set is indeed different from the (mereological) way in which a hydrogen atom is a part of, say, a water molecule. However, we should not think that the latter case is somehow really about parthood while the former is just a mere façon de parler. Following Fine (2010, p. 560), the member of a set is in the set in the sense of being integral to the set (as opposed to being enclosed in the set like a person is in a room). See also Fine (2010, §VII) where he discusses the notion of K-part.
} 
The fact that Socrates is a member of \{Socrates\} is always grounded in some facts about how he relates to \{Socrates\}, such as, for instance, [Socrates exists and necessitates \{Socrates\}'s existence]. Another very plausible suggestion is the following one: [Socrates instantiates being a member of \{Socrates\}] is grounded in [Socrates stands in the relation being a member of to $\{$ Socrates $\}]$; using $\lambda$-notation, we can express this idea as follows: $[\lambda x(x \in\{$ Socrates $\})$ (Socrates) $]$ is grounded in $[\lambda x y(x \in y)$ (Socrates, $\{$ Socrates\})]. In either case, the ground involves an entity, $\{$ Socrates $\}$, which is not a *part of Socrates. Thus, being a member of \{Socrates\} is not intrinsic to Socrates and we can conclude that (CMAG) does not classify this property as essential to Socrates. To put it another way, it follows from (CMAG) that (1) is false, which is the correct result.

What about containing Socrates? Is it an essential property of \{Socrates\}? With respect to (G), it is plausible to hold that for all $\varphi$ and all $y$ such that $\{$ Socrates $\}$ contains Socrates in virtue of $\varphi(y), y$ is a part of \{Socrates\}. The fact that \{Socrates $\}$ contains Socrates is also always grounded in some fact about how \{Socrates \} relates to Socrates, such as, for instance, [ $\{$ Socrates $\}$ exists and its existence is necessitated by Socrates's existence]. Or to pursue the strategy mentioned above, we can use the $\lambda$-notation to express the idea that the relational property is grounded in the relation: [ $\lambda x$ (Socrates $\in x)(\{$ Socrates $\})]$ is grounded in $[\lambda x y(x \in y)$ (Socrates, \{Socrates $\})]$. In either case, the ground involves an entity, Socrates, which is a *part of \{Socrates\}. Hence, we can safely assume that (G) is satisfied and it follows that, according to (CMAG), it is essential for \{Socrates\} to contain Socrates-i.e., (2) is true. ${ }^{24}$ Let me now clarify how we should understand the idea that set-members are *parts of the sets to which they belong.

When Socrates comes into existence so does $\{$ Socrates\}, and as soon as Socrates ceases to exist, so does \{Socrates\}. My point is that the relation that holds between these two entities is very similar to the mereological relation that holds between a whole and its proper part(s). Think, for instance, about a water molecule composed of its three constituent atoms: if one splits the molecule, it will lose its constituent atoms - which are its parts - and no longer be what it was. The situation is similar in the case of Socrates and his singleton: if \{Socrates\} 'loses' Socrates as a member-or, equivalently, if Socrates ceases to exist— - Socrates\} will no longer be what it was; how could it? Thus, such a scenario is totally different from Denby's example involving Socrates and his dog, because as explained above, \{Socrates \} cannot exist without Socrates. Of course, Denby is right when he thinks that two wholly distinct entities cannot have any intrinsic connection. But the subtle point here is that even if Socrates and \{Socrates\} are distinct entities, they are distinct in a different way, that is, distinct in the sense that no proper part is identical with the whole. It is partly because he fails to appreciate this important point that Denby sees himself forced to deny that $\{$ Socrates contains Socrates essentially. So in response to Denby's challenge- 'how could a set—or anything else—intrinsically involve something distinct from itself?' - the answer is: 'in each scenario involving a thing and its *parts'. The fact that Socrates and \{Socrates\} belong to two different ontological categories plays

\footnotetext{
${ }^{24}$ I am particularly indebted to F. Correia, T. Wilsch, and a referee for Synthese for their helpful suggestions regarding the grounds of Socrates's being a member of $\{$ Socrates $\}$ and $\{$ Socrates $\}$ containing Socrates.
} 
no role whatsoever in the relationship that holds between them and, most importantly, should not prevent us from appreciating the fact that there is nothing puzzling or obscure about the position that Socrates is a *part of \{Socrates\}. Actually, could we not say that the relation between \{Socrates\} and Socrates is a rather enlightening and paradigmatic instance?

Just consider the matter the other way around: why is it not plausible to say that Socrates's existence depends on \{Socrates\}'s? Partly because the latter is not a *part of the former: to be a member of $\{$ Socrates $\}$ is to be a *part of $\{$ Socrates $\}$, and in this case the property being a member of \{Socrates\} expresses the relation from the grounding entity to the grounded entity (while containing Socrates expresses the relation the other way around). In this sense, then, the property being a member of \{Socrates\} is what determines that only Socrates (the bearer) is a *part of \{Socrates\} (and not his fingers, hairs, etc. which do not-and obviously cannot-instantiate the property of being a member of \{Socrates\}). ${ }^{25}$ In other words, the membership property ensures that there is no transitivity of parthood that goes from Socrates's proper parts to \{Socrates\}; only Socrates's improper part (i.e., Socrates) instantiates the membership-property. This, I take it, is precisely how it should be.

At this point, I conclude that, in accordance with (G), containing Socrates rightfully qualifies as an intrinsic property of $\{$ Socrates $\}$, and thus that it is an essential property of \{Socrates\} (and of all sets containing Socrates for that matter). In short, $\{$ Socrates $\}$ has containing Socrates essentially because Socrates is a *part of \{Socrates\}. So it follows that in addition to the falsity of (1) (it is essential to Socrates to belong to \{Socrates\}), (CMAG) also entails the truth of (2) (it is essential for \{Socrates\} to contain Socrates). As such, (CMAG) successfully meets the essentialist challenge.

In order to demonstrate the explanatory power of (CMAG), let me apply the present investigation to Fine's other counterexamples. Remember that (CMA) ascribes being distinct from the Eiffel Tower as an essential property of Socrates. This property cannot satisfy (G) for reasons that should be obvious. Indeed, Socrates is distinct from the Eiffel Tower partly in virtue of the fact that he is a human being and the Eiffel Tower is a metallic construction, in which case the Eiffel Tower is not a * part of Socrates. ${ }^{26}$ Hence, being distinct from the Eiffel Tower is not intrinsic and therefore not essential to Socrates. Furthermore, for most similar cases of numerical distinctness where the entities considered are wholly distinct, $(\mathbf{G})$ will bring such a successful result.

We can also be confident that $(\mathbf{G})$ excludes necessary properties like being such that $2+2=4$ or being such that there are infinitely many primes counting as essential to Socrates. For instance, if - as Fine does-one admits concepts, logical operators, numbers, propositions, etc., in one's ontology, it is clear that if Socrates is such that $2+2=4$, it is certainly not in virtue of something that is a *part of Socrates. Hence this property is neither intrinsic nor essential to Socrates. However, with necessary instantiated properties such as being $F$ or non- $F$, matters are somehow trickier. Let

\footnotetext{
25 In a similar vein, Armstrong explains that in order to "be a member there must be something about it that makes it a one: that sets the one's boundaries as it were. And what can this something be except something about the nature of the one: some property that does the one-making?" (Armstrong 1991, p. 198).

26 Other explanations could be that Socrates $\neq$ Eiffel Tower because Socrates bears the relation being distinct from to the Eiffel Tower or, as N. Wildman pointed out to me, because Socrates instantiates being Socrates and the Eiffel Tower instantiates being the Eiffel Tower.
} 
me try to elaborate how such cases can be handled by considering Socrates's being a mountain or not being a mountain.

Given that Socrates instantiates that property in each and every world in which he exists, the question is whether or not it is one of his intrinsic properties. One could answer that Socrates is a mountain or not a mountain in virtue of the fact that he is not a mountain; and it can be argued that Socrates is not a mountain because mountains are composed of sedimentary and/or igneous rocks, and are raised parts of the Earth's surface - and all these things (the rocks and the Earth's surface) are not *parts of Socrates. Thus, Socrates is not essentially a mountain or not a mountain but, arguably, merely necessarily so. The instantiation of such disjunctive properties is grounded in one of the disjuncts (the positive or the negative one), and once we find out which disjunct corresponds to the property instantiated by $x$, we then proceed to find out whether or not the property is intrinsic to $x .{ }^{27}$ Consequently, if the property in question is intrinsic to $x$, it will turn out that it is an essential property of $x$. But does that make the disjunctive property essential to $x$ ? I believe so, but this can be seen as a fact that merely follows from the fact that $x$ instantiates a property-i.e., [F $x \bigvee$ $\neg \mathrm{F} x]$ obtains in virtue of either $[\mathrm{F} x]$ or $[\neg \mathrm{F} x]$, but not the other way around. As a last remark, let me stress that one can have reasons to think that there are no disjunctive and/or negative properties; in this case the issue does not even arise.

With respect to existing, there is a long tradition tracing back to (at least) Kant and Hume that denies it to be a property. But interestingly enough, there are different interpretations of what existing can mean in a particular use. For instance, one might claim that existence is identical to the property occupying a spatiotemporal point. In such a case, if one applies (G), it is obvious that this property is not intrinsic, for a spatiotemporal point, $\mathrm{S}$, is arguably not a *part of S's occupant. Hence, if existing is construed as such, it does not qualify as an essential property of, say, Socrates. The special case of existence is - and will probably always be - controversial, and I shall not take a stance on this specific philosophical issue here. (Note that the interpretation of existence that I have just sketched might not apply to abstract objects, for they are presumably not spatiotemporally located.)

Finally, what about haecceities such as being Socrates? They are intrinsic properties, because if something is Socrates it is in virtue of how that thing is as opposed to how the rest of the world is. (G) nicely accommodates this idea, for Socrates is Socrates in virtue of the fact that he exists, in which case Socrates is a *part of Socrates. This is nothing but a clear case of individuation, because one is not saying that Socrates is a proper *part of himself, but rather that he is a *part identical to himself-i.e., Socrates is an improper *part of Socrates. (If one is resistant to this explanation, I see no obstacle to adjusting (CMAG) with a disjunctive clause for haecceities.)

So as far as I can tell, (CMAG) is a reductionist account of essence that overcomes the essentialist challenge. And to that extent, I find this general picture both conclusive and compelling. But, perhaps, matters are not so simple. I will now investigate some

\footnotetext{
27 As an anonymous referee has pointed out to me, it might very well be the case that [Socrates is not a mountain] is fully grounded in something like [Socrates only has such-and-such parts]. This turns out to be important if the property in question is a sortal property. I return to this point in Sect. 4 where I discuss how (CMAG) accommodates sortal essentialism.
} 
difficulties that should be kept in mind, if one is willing to endorse this analysis, and I will also provide some suggestions as to how one can address them.

\section{Difficulties and objections: grounding, sortals, origins, and natural kinds}

Let us start with issues specific to (G), and with a brief comparison with Lewis's (1986) account of intrinsic properties. One consequence of the latter is that it classifies all perfectly natural properties as intrinsic. As a response, Yablo (1999) objected that if, for some reason, a perfectly natural property $\mathrm{F}$ fails to be intrinsic, Lewis's account will classify $\mathrm{F}$ as intrinsic no matter what. In other words, this means that Lewis's account excludes from the outset the possibly of extrinsic perfectly natural properties. In addition to this, even if it happens to be true that there are absolutely no extrinsic perfectly natural properties whatsoever, Yablo (1999) explains that it is a matter of 'luck' that Lewis's account gives the correct result. This is so because there is nothing in the nature of intrinsicality itself that predicts that there a no extrinsic perfectly natural properties (ibid., p. 480).

A very similar situation arises with $(\mathbf{G})$ : what if $\mathrm{F}$ is a fundamental property of $x$ ? Arguably, (G) automatically classifies F as intrinsic to $x$. If this is so, (G) cannot make sense of the idea that some fundamental facts may state the extrinsic possession of a property by an entity. Thus, one might press the same Yablo-inspired objection against (G) that can be pressed against Lewis's account: even if it happens to be correct that any entity possesses each of its fundamental properties intrinsically, it seems to be a purely contingent matter that $(\mathbf{G})$ provides this result. These worries are common to all hyperintensional accounts of intrinsicality. As a response, I side with Bader who explains that entities cannot possess any fundamental property extrinsically because

properties that are had extrinsically are all derivative and to be found at nonfundamental levels. They are derivative because all extrinsic properties are relational in character and properties that are relational in character derive from the obtaining or non-obtaining of relations and are consequently nonfundamental. [...] Alternatively, if a property is fundamental, then it cannot be had in virtue of any relations and if it is not had in virtue of any relations, then it is had intrinsically (Bader 2013, p. 557, emphasis mine). ${ }^{28}$

Hence, properties that are possessed extrinsically cannot be fundamental, and it is not a matter of luck that entities instantiate their fundamental properties intrinsically, but precisely as it should be. ${ }^{29}$ Furthermore, Bader's explanations are based on the intuitive and plausible idea that, metaphysically speaking, a particular relation is not derived from the particular instances of a relational property, but rather the other way around. Inter alia, this secures the idea that the relational property being a member

\footnotetext{
28 If one feels uneasy with the assumption that fundamental properties are intrinsic, a possible maneuver would be to say that if a fundamental property $\mathrm{F}$ grounds extrinsic facts (such as [Fa] grounds [aRb] for instance), $\mathrm{F}$ is not intrinsic. This involves considerations about downstream grounding.

29 See also Bader (2013, p. 560) for the reasons why hyperintensional accounts of intrinsicality successfully avoid the difficulties by those that rely on the notion of perfectly natural properties such as Lewis (1986).
} 
of \{Socrates\} is never possessed fundamentally by Socrates, as it is always grounded in - and hence explained by-the fact that Socrates and \{Socrates\} stand in the setmembership relation. ${ }^{30}$

Another potential issue is number necessitarianism. Marshall objects that (RI) (i.e., Rosen's account of intrinsic properties) classifies existing as an extrinsic property of numbers because "it is plausible that it is a law that each number has a successor, and, given this, it is plausible that the existence of each number $n+1$ is grounded by the existence of its preceding number $n$ " $(2015$, p. 13). Given that (G) relies on the grounding relation, it faces exactly the same issue. However, with the general notion of parthood endorsed in the present work, there is a way to overcome this kind difficulty. If we opt for the view according to which $0=\emptyset, 1=\{\emptyset\}, 2=\{\emptyset$, $\{\varnothing\}\}$, etc., we can argue that 2 exists in virtue of the fact that 1 exists, in which case 1 is a *part of 2 , etc. for all numbers. Note that this strategy implies that numbers exist essentially—an idea to which I am not opposed.

Competing characterizations of intrinsic properties have been subject to different counterexamples, and I will mention two of them. The first one is due to Marshall and Parsons (2001) who have objected to Langton and Lewis's (1998) account of global intrinsicality that it classifies the property being such that there is a cube as intrinsic, while intuitively this is not (universally) so. The upshot with (G) is that we can make sense of the idea that this property is intrinsic to the Rubik's Cube on my desk but not intrinsic to me. (Note that, by itself, this particular example reinforces the idea that we should opt for a notion of local intrinsicality rather than global one.) Moreover, Langton and Lewis's account has been subject to criticisms from Sider (2001) who argues that it classifies maximal properties—such as being a house and being a rock-as intrinsic, while such properties are extrinsic. I will discuss this point in connection with sortal essentialism shortly.

The second important difficulty for characterizations of intrinsicality concerns the property of being lonely. Intuitively, this property is extrinsic to the objects that instantiate it because for a given $x$ to be lonely, it must be the case that no contingent thing wholly distinct from $x$ coexists with $x$. Finding the grounds of negative facts turns out to be a rather technical (and tricky) issue. (In particular, this property is so problematic that Langton and Lewis's account of intrinsicality is entirely framed around it.) A straightforward solution to this problem requires an investigation on its own as well as an analysis of what it is for a property to be extrinsic to an entity. However, for the scope of this paper this problem can be accommodated by saying that a property $\mathrm{F}$ is not intrinsic to $x$ if there is a sufficient ground that involves quantification to ground $[\mathrm{F} x]$. The reason behind the exclusion of quantificational facts is that one needs to quantify beyond the boundaries of the object to ground the fact that the object possesses such-and-such property. ${ }^{31}$ Hence, given that $[x$ is lonely] is arguably grounded in $[\forall y(y$ exists $\supset y \prec x)$ ], it follows that being lonely is not intrinsic to $x$ (even though there is nothing that exists contingently outside of $x$ ). ${ }^{32}$

\footnotetext{
30 I am particularly indebted to an anonymous referee for Synthese for pushing me to clarify my explanations on fundamentality and for suggesting this particular line of response.

31 Thanks to T. Wilsch for suggesting this specific solution.

32 F. Correia has suggested to me another way to deal with the property being lonely by construing the universal quantifier in (G) as possibilist. If we suppose that $x$ is lonely in the actual world, @, that means
} 
Fig. 1 Being a rock

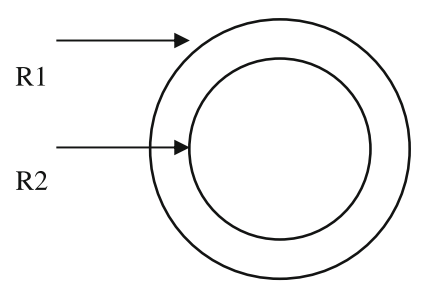

Let us now turn to what I consider as the most serious concern: even if (CMAG) successfully meets the essentialist challenge, we might still wonder to what extent this account can meet the essentialist desideratum. In the literature, philosophers have successively endorsed — and, to a certain extent, also rejected — three major essentialist claims: sortal essentialism, origin essentialism, and natural kinds essentialism. (I assume here that the reader is familiar with each of these claims. ${ }^{33}$ ) I shall now evaluate an example of each of these claims with respect to (CMAG) and conclude with a brief discussion on self-identity and haecceities.

Sortal essentialism. Sider (2001) argues that the possession of maximal properties is (partly) an extrinsic matter. The problem is that among maximal properties we find sortal properties such as being a rock, being a cat, etc. ${ }^{34}$ Sider thinks that such properties are extrinsic to their bearer because, for instance, for R1 to be a rock is for $\mathrm{R} 1$ to be such that its constituents are arranged in a certain 'rocky'-way, and also for $\mathrm{R} 1$ to be such that it is not a part of any slightly larger rock. ${ }^{35}$ An illustration might help (Fig. 1 being a rock):

According to Sider, both R1 and R2 have what it intrinsically takes to be a rock, and yet only R1 exemplifies being a rock. Why? Because R1 is not a part of any larger rock. Accordingly, R2 does not instantiate being a rock because it is a part of R1. So if $\mathrm{R} 1$ is a rock, then its being a rock crucially depends on what is the case outside of R1's boundaries/surface, and thus being a rock is not intrinsic to R1. (A similar reasoning applies to $\mathrm{R} 2$ not being a rock.) Thereby, if (G) does not classify being a rock as intrinsic to $\mathrm{R} 1$, it follows that this property is not essential to $\mathrm{R} 1$ - which seems counterintuitive. So how does $(\mathbf{G})$ stands with respect to maximal properties? It depends on one's view about what grounds [R1 is a rock]. I will not try to give a

\section{Footnote 32 continued}

that for every possible object $y$, if $y$ exists in @, then $y$ is a part of $x$. The grounds of $[x$ is lonely in @] are arguably all facts of the type [if $\alpha$ exists in @, then $\alpha$ is a part of $x$ ], [if $\beta$ exists in @, then $\beta$ is a part of $x$, etc. In this case, we find facts about possible objects that do not exist in @ and that are not parts of $x$. Hence, being lonely is not intrinsic to $x$.

Thanks to an anonymous referee for Synthese for pointing to me that (G) does not accommodate being lonely as straightforwardly as I initially thought, and thanks to T. Wilsch and M. De for their very helpful comments.

33 If not, I redirect the reader to Robertson and Atkins (2018).

34 There are variant and invariant sortals. For the present discussion, I have in mind the invariant sortalsi.e. sortals that objects cannot fail to instantiate (Sattig 2015, p. 15).

35 One of Sider's examples to illustrate this point is the following: "[T]he property being a house is not an intrinsic property. For inspection of a thing - for example, House-minus - will not reveal whether it is a house; one must additionally inspect whether it is attached to other things that would collectively compose a house" (Sider 2001, p. 357). 
definitive answer about whether or not being a rock is intrinsic to R1 here. Rather, I will briefly sketch two alternatives that I consider worth discussing.

The problem with $\mathrm{R} 1$ is to find a fact that contains some $y$ to ground [R1 is a rock] and to determine whether $y$ is a part of R1 or not. For instance, one could follow Sider's intuition and say that, in the actual world, ${ }^{36}[\mathrm{R} 1$ is a rock $]$ is grounded in the fact [R1 does not overlap with $x 1, x 2, \ldots, x n$ etc. where the $x i$ are all the rocks in the spatiotemporal region surrounding R1]. None of the $x i$ are parts of R1 and (G) is not satisfied. ${ }^{37}$ However, that kind of explanation is strange, because all rocks existing in the vicinity of R1-no matter how numerous they are-are partial grounds of [R1 is a rock]. ${ }^{38}$ To vindicate Siders's intuitions, we could also pursue the idea that if the fact that an entity possesses a property is grounded in a fact involving quantification, the property is not intrinsic to the entity. Such a fact could be [ $\forall y$ ( $y$ is composed of the same rocky material as $\mathrm{R} 1 \supset y$ does not surround $\mathrm{R} 1)]$.

With the exception of philosophers such as Mackie (2006), few essentialists would accept the conclusion that sortal properties are not essential to their bearers. In fact, one of the paradigmatic examples given in the literature is that of Socrates being essentially human. Independently from that point, one might also simply think that sortal properties are possessed intrinsically. This amounts to deny-contra Sider - that what it intrinsically takes to be a rock is not sufficient to be a rock, and argue that [R1 is a rock] is fully grounded in facts about R1 and its parts. Yet if that is the strategy adopted, one faces Unger's Problem of the Many (1980): instead of there being exactly one rock, R1, there are infinitely many rocks. Each part of R1-including R2-is an equal and legitimate candidate at being a rock. Sattig $(2013,2015)$ has offered a promising way to deal with this specific problem. The details are quite technical to be fully developed here, but applied to our example, Sattig's core idea consists in saying that R1 is a rock-and not R2-because R1 is a maximal fusion $\mu$ of massively overlapping rock-objects, and that the principle of extensionality ensures that there is exactly one unique $\mu(2013$, p. 11). Hence, if one is willing to opt for Sattig's framework, then it is possible to defend the idea that sortal properties are intrinsic and therefore essential to their bearers. ${ }^{39}$

To conclude this discussion on sortal properties, remember that in Sect. 3 I provided grounds to sustain the claim that being not a mountain is not intrinsic to Socrates. But given the previous explanations, it is tempting to say that Socrates is not a mountain in virtue of the fact that he is human or maybe because he intrinsically possesses what it takes to be human (in virtue of compositional facts for instance). Thus, if this is one's

\footnotetext{
36 Of course, matters will be different if we consider a possible world $w$ where $\mathrm{R} 1$ is the only rock. For simplicity I just stick to the example given in the text.

37 Thanks to M. De for discussing this example and his helpful comments about maximality and grounding.

38 Fair enough, but if we really follow what Sider says, this is pretty much how the explanation should go. And the strangeness of the explanation is not due to (G), but rather to Siders's intuitions. Independently of the essentialist debate, the question of what are the grounds of [R1 is a rock] is difficult to answer if one follows strictly what Sider says.

39 There are probably exceptions which partly depend on the world in which the fact involving an object instantiating a sortal property is evaluated. For a discussion on this point see chapter 1 of Sattig's (2015).
} 
preferred view on the matter, it will be essential to Socrates that he is not a mountain, not a cat, etc. ${ }^{40}$

Origin essentialism. There are many more controversies and debates around the question of whether origins are essential to their bearers than there are about sortal essentialism. ${ }^{41}$ Some philosophers, e.g., Forbes (1985), Noonan (1983), and Salmon (1981), have provided refined arguments in favor of Kripke's initial thoughts on origin essentialism. Others such as Mackie (2006) and Robertson (1998) have severely criticized the idea that this view - at least as conceived and defended by their rivals - can be sustained. Let us now briefly survey what are the important points to bear in mind in order to accommodate or reject origin essentialism with respect to (CMAG). For simplicity, I focus here on the origins of human beings, but with minor changes, the discussion applies to other organisms and artifacts as well.

To begin with, when we talk about the origins of a human being, we talk about the zygote from which that human being developed. A popular view in the literature is that origins are both extrinsic and essential to their bearers. As Yablo puts it, origin properties are essential, "but on almost anybody's account, the zygote stopped existing before [Socrates] started-whence descending from [this zygote] is an extrinsic property of [Socrates]" (Yablo 1999, p. 486). Clearly, this thesis is at odds with (CMAG), given that essential properties must be intrinsic. As a natural response, one might argue instead that origins are intrinsic (and essential) to their bearers. For the present discussion, the extrinsic vs. intrinsic origins debate should be scrutinized through the lens of $(\mathbf{G})$ in order to see how we can reach either conclusion.

According to (G), the claim that Socrates possesses his origins extrinsically amounts to the claim that among the facts $\varphi(y)$ in virtue of which Socrates originates from $z$, there is some fact that involves a $y$ that is not part of Socrates. Arguably, Socrates originates from $z$ in virtue of some biological/developmental facts involving $z$. So the issue at stake here is: is $z$ a part of Socrates? If one sides with Yablo, $z$ is not a part of Socrates because $z$ ceases to exist before Socrates starts to exist. However, this particular view is not forced upon anyone, as some philosophers have argued that zygotes are parts of their bearers. For instance, McGinn (1976) and Simons (1987) think that at some point in the existence of a human being, the zygote is identical to-and hence an improper part of-that human being. ${ }^{42}$. There is room for debate here, and it should be noted that even if one thinks that origins are extrinsic, my

\footnotetext{
40 A referee has stressed some concern about being not a round-square which is not a sortal property. Is this property intrinsic to Socrates? As I have just explained above with the mountain-example, it is hard to give a definitive answer. As a response, one could opt for the general strategy I mentioned, which consists in saying that if [Socrates is not a round-square] is grounded in a fact involving quantification, the property is not intrinsic to Socrates. In the present case, the ground is arguably $[\neg \exists x(x$ is a round $\& x$ is a square $)]$. But maybe one might want to argue that [Socrates is not a round-square] is grounded in [Socrates is human]. In this case, compositional facts and/or other facts involving what it takes intrinsically to be a human, a cat, a rock, etc., can be considered as sufficient grounds. I leave this question open to further considerations.

41 See Robertson and Atkins (2018) for a detailed survey of the arguments for and against origin essentialism.

42 For criticism of McGinn's view see Forbes (1985, pp. 134-137).

In connection to the origins/parthood discussion, there is a sensitive ethical issue regarding the conceptionist vs. anti-conceptionist debate. Typically, conceptionists endorse endurantism as a theory of persistence. Yet, this particular view makes conceptionism vulnerable to the twining argument. In order to address the latter, conceptionists can opt for perdurantism as a theory of persistence and argue that human
} 
account does not rule out ab initio that it is necessary for a given $x$ to have the origins it has if it exists. If this claim is successfully defended, it will not be part of the nature of a thing to possess the origins it has. Note also that (CMAG) is compatible with property-variations between entities. That is, maybe it is not essential (and even not necessary) to human beings to have the particular origins that they have, but (CMAG) can certainly accommodate the idea that some other species or God—arguably a sui generis entity - possesses its own origins intrinsically (i.e., in virtue of facts involving God and its proper parts only) and therefore essentially.

In sum, philosophers who reject the idea that origins are essential to their bearers should - if they endorse (CMAG) — argue that the origins are not part of their bearers and/or, in the same vein as Mackie (2006), defend the view that it is not necessary that if a thing, $x$, exists, then $x$ has the origins it actually has. If, on the other hand, one is willing to endorse both origin essentialism and (CMAG), then one has to argue that the origins of $x$ are part of $x$ and that it is necessary that if $x$ exists, then $x$ has the origins it actually has.

Natural kinds essentialism. Roca-Royes defines natural kinds essentialism as follows: "if instances (or samples) of a given kind, $k$, have structure $x$ (be this microphysical structure, biological structure, chemical structure, etc.), then, it is essential to $k$ that all its instances (or samples) have structure $x$ " (2011, p. 70). Given this definition, a natural reaction is to say that being such that all its instances (or samples) have structure $x$ does not count as intrinsic to a given kind $k$. For according to (G), if $k$ instantiates this property, then it is in virtue of facts involving instances (or samples) that are not parts of $k$. Philosophers who are unsympathetic to natural kinds essentialism can be happy with this result. But if one wants to endorse (CMAG) and defend natural kinds essentialism, then one has to find a way to say that the instances of a kind are parts of that kind. As a response, one could extend the general notion of parthood involved in $(\mathbf{G})$ so as to argue that the instances of a given kind, $\mathrm{K}$, belong to $\mathrm{K}$ (in a similar vein that set-members belong to sets). In this case, the instances of $\mathrm{K}$ will count as *parts of $\mathrm{K}$ and it will be intrinsic and hence essential to $\mathrm{K}$ to be such that all its instance (or samples) have structure $x$. If this is not convincing, another straightforward move is to endorse perdurantism as a theory of persistence, and argue that $\mathrm{K}$ is nothing over and above the sum of all spatiotemporal parts that are occupied by each of its instances (or samples). At last, let me stress that Roca-Royes's above definition serves as an illustrative example of how an account of natural kinds essentialism might go, but it is certainly not universally endorsed. Hence, one has to figure out how one's favorite account of natural kinds works along with (CMAG).

If one endorses (CMAG), one should provide substantial argument in favor of the claims that it is essential for Socrates to be human and to have the origins he has, as well as arguments in favor of natural kinds essentialism. But this is not specific to (CMAG). Indeed, for instance, proponents of (CMA) also have to support their intuitions in favor or against the idea that Socrates is essentially human, and Fine's definitional account is badly in need of argument to this effect. Further considerations

Footnote 42 continued

beings have their zygote as a temporal part. For a discussion of this specific issue, see Efird and Holland (2019). 
are also needed in cases where objects possess dispositional/functional essences. ${ }^{43}$ The question turns out to be whether dispositions are just intrinsic to the objects that possess them or not. Of course, if there are extrinsic dispositions, it is a consequence of my account that they will not count as essential. However, there are also popular views according to which most dispositions are grounded in an intrinsic categorical base and in this case, the account I offer is compatible with these views. ${ }^{44}$

Finally, let us consider the logical property being self-identical which is arguably intrinsic - and therefore essential - to each and every entity. One might think that, prima facie, there is no valuable reason to deny that this property is essential to absolutely everything. However, this is problematic — and yet not specific to (CMAG). For I do not see how one can successfully grasp Socrates's nature when one is told that 'part of what it is to be Socrates is to be self-identical', or that 'Socrates is essentially identical to himself' ${ }^{45}$ The very same situation arises with haecceities, because it is clear that, with respect to the essentialist desideratum, one does not grasp what Socrates is if one is told that Socrates is Socrates. Be that as it may, I do not see why we should not make an exception for self-identity and haecceities, taking them to be intrinsic and essential to their bearers no matter what. I contend that this is far less controversial than Denby's stance on this same issue.

Given the previous explanations, my first thought is that (CMAG) constitutes a fine-grained yet controversial analysis of essence. On the one hand, it offers a straightforward solution to the essentialist challenge, on the condition, of course, that one accepts the general notion of parthood I have suggested and assumes the grounding relation. The upshot is that (CMAG) allows one to distinguish between the merely necessary and the essential properties of an entity, and provides a clear criterion to single out these properties. On the other hand, by endorsing (CMAG) it is not possible to stay neutral with respect to further metaphysical issues: origin and natural kinds essentialism, if defended, require the endorsement of theses about the mereology and persistence of material objects; and sortal essentialism, if endorsed, forces one to deal with Unger's Problem of the Many. With respect to these points, (CMA) is metaphysically neutral.

To conclude, simple modal characterizations of essence such as (CMA) are, as Fine correctly argues, untenable at the condition of course that one takes them seriously as I did in this paper. Throughout the present discussion, I have argued in favor of the idea that a specific criterion of intrinsicality can be used to successfully address each of Fine's counterexamples. I am aware that the general picture I propose can be seen as theoretically costly, but I think that we should not overlook its explanatory power: it provides actual as well as possible future answers. Further investigations are needed in order to see if after all, Fine might be right to think of essence as a primitive notion and as prior to modality. Be that as it may, I hope that I have nonetheless shed some new light on essentialism and intrinsicality, and especially on what it takes to defend

\footnotetext{
43 Thanks to an anonymous referee for Synthese for stressing this point.

44 See McKitrick (2003) for a detailed discussion on the intrinsic versus extrinsic dispositions debate.

45 See Spinelli (2019) for a thorough investigation of this question with respect to (CMA) and Finean essentialism.
} 
this idea. It might very well turn out that $(\mathbf{G})$ proves useful if considered on its own or for other philosophical purposes.

Acknowledgements Open Access funding provided by Projekt DEAL. I am particularly indebted to Fabrice Correia for his guidance, support, and invaluable comments throughout the whole writing process of this paper. I am also grateful to Hagen Braun, Michael De, Richard Glauser, Daniel Gregory, Jan Plate, Thomas Sattig, Maria Scarpati, Alex Skiles, Michi Wallner, Nathan Wildman, Tobias Wilsch, three anonymous referees for Synthese, and the audience at the Issues on the (Im)Possible VI conference, whose constructive and insightful comments have helped me improve the present paper significantly. For her unconditional support, my heartfelt thanks go to Yun Lin.

Open Access This article is licensed under a Creative Commons Attribution 4.0 International License, which permits use, sharing, adaptation, distribution and reproduction in any medium or format, as long as you give appropriate credit to the original author(s) and the source, provide a link to the Creative Commons licence, and indicate if changes were made. The images or other third party material in this article are included in the article's Creative Commons licence, unless indicated otherwise in a credit line to the material. If material is not included in the article's Creative Commons licence and your intended use is not permitted by statutory regulation or exceeds the permitted use, you will need to obtain permission directly from the copyright holder. To view a copy of this licence, visit http://creativecommons.org/licenses/by/4.0/.

\section{References}

Allen, S. R. (2016). A critical introduction to properties. London, UK: Bloomsbury Publishing.

Armstrong, D. M. (1991). Classes are states of affairs. Mind, 100(2), 189-200.

Bader, R. M. (2013). Towards a hyperintensional theory of intrinsicality. The Journal of Philosophy, 110(10), $525-563$.

Bagaria, J. (2017). Set theory. The stanford encyclopedia of philosophy. Retrieved from https://plato. stanford.edu/archives/sum2017/entries/settheory/.

Brogaard, B., \& Salerno, J. (2007). A counterfactual account of essence. The Reasoner, 4, 4-5.

Correia, F. (2007). (Finean) essence and (Priorean) modality. Dialectica, 61(1), 63-84.

Correia, F., \& Skiles, A. (2017). Grounding, essence, and identity. Philosophy and Phenomenological Research, 98(3), 642-670.

Cowling, S. (2013). The modal view of essence. Canadian Journal of Philosophy, 43(2), 248-266.

Della Rocca, M. (1996). Essentialism. Philosophical Books, 37, 1-13 and 81-89.

Denby, D. (2014). Essence and intrinsicality. In R. Francescotti (Ed.), Companion to intrinsic properties (pp. 87-109). Berlin: De Gruyter.

Dunn, J. M. (1990a). Relevant predication 2: Intrinsic properties and internal relations. Philosophical Studies, 60(3), 177-206.

Dunn, J. M. (1990b). Relevant predication 3: Essential properties. In M. Dunn \& A. Gupta (Eds.), Truth or consequences: Essays in honor of Nuel Belnap (pp. 77-95). Dordrecht: Springer.

Eddon, M. (2011). Intrinsicality and hyperintensionality. Philosophy and Phenomenological Research, 82(2), 314-336.

Efird, D., \& Holland, S. (2019). Stages of life: A new metaphysics of conceptionism. Bioethics, 33(4), 529-535.

Fine, K. (1994). Essence and modality. Philosophical Perspectives, 8, 1-16.

Fine, K. (2009). The question of ontology. In D. Chalmers, D. Manley, \& R. Wasserman (Eds.), Metametaphysics (pp. 157-177). Oxford: Clarendon Press.

Fine, K. (2010). Towards a theory of part. The Journal of Philosophy, 107(11), 559-589.

Forbes, G. (1985). The metaphysics of modality. Oxford: OUP.

Forbes, G. (2001). Origins and identities. In A. Bottani, D. Giaretta, \& M. Carrara (Eds.), Individuals, essence and identity, themes of analytic metaphysics (pp. 319-340). Dordrecht: Kluwer.

Gorman, M. (2005). The essential and the accidental. Ratio, 18(3), 276-289.

Langton, R., \& Lewis, D. (1998). Defining 'intrinsic'. Philosophy and Phenomenological Research, 58(2), 333-345.

Lewis, D. (1986). On the plurality of worlds. Oxford: Blackwell. 
Livingstone-Banks, J. (2017). Defence of modal essentialism. Inquiry, 60(8), 816-838.

Lowe, E. J. (2008). Two notions of being: Entity and essence. Royal Institute of Philosophy Supplements, $62,23-48$.

Mackie, P. (2006). How things might have been: Individuals, kinds, and essential properties. Oxford: OUP.

Marshall, D. (2015). Intrinsicality and grounding. Philosophy and Phenomenological Research, 90(1), $1-19$.

Marshall, D., \& Parsons, J. (2001). Langton and Lewis on 'intrinsic'. Philosophy and Phenomenological Research, 63, 347-351.

McGinn, C. (1976). On the necessity of origin. The Journal of Philosophy, 73(5), 127-135.

McKitrick, J. (2003). A case for extrinsic dispositions. Australasian Journal of Philosophy, 81(2), 155-174.

Noonan, H. (1983). The necessity of origin. Mind, 92, 1-20.

Plate, J. (2018). Intrinsic properties and relations. Inquiry, 61(8), 783-853.

Rayo, A. (2015). Essence without fundamentality. Theoria, 30(3), 349-363.

Robertson, T. (1998). Possibilities and the arguments for origin essentialism. Mind, 107(428), 729-750.

Robertson, T., \& Atkins, P. (2018). Essential versus accidental properties. The Stanford Encyclopedia of Philosophy. Retrieved from: https://plato.stanford.edu/archives/spr2018/entries/essential-accidental/.

Roca-Royes, S. (2011). Essential properties and individual essences. Philosophy Compass, 6(1), 65-77.

Romero, C. (2018). Modality is not explainable by essence. The Philosophical Quarterly, 69(274), 121-141.

Rosen, G. (2006). The limits of contingency. In F. MacBride (Ed.), Identity and modality (pp. 13-39). Oxford: OUP.

Rosen, G. (2010). Metaphysical dependence: Grounding and reduction. In B. Hale \& A. Hoffman (Eds.), Modality: Metaphysics, logic, and epistemology (pp. 109-135). Oxford: OUP.

Salmon, N. (1981). Reference and essence. Princeton: Princeton University Press.

Sattig, T. (2013). Vague objects and the problem of the many. Metaphysica, 14(2), 211-223.

Sattig, T. (2015). The double lives of objects: An essay in the metaphysics of the ordinary world. Oxford: OUP.

Schaffer, J. (2010). Monism: The priority of the whole. Philosophical Review, 119(1), 31-76.

Schaffer, J. (2016). Grounding in the image of causation. Philosophical Studies, 173(1), 49-100.

Sider, T. (2001). Maximality and intrinsic properties. Philosophy and Phenomenological Research, 63, 357-364.

Simons, P. (1987). Parts: A study in ontology. Oxford: OUP.

Skiles, A. (2015). Essence in abundance. Canadian Journal of Philosophy, 45(1), 100-112.

Spinelli, N. (2019). Is self-identity essential to objects?. Synthese, 1-17.

Teitel, T. (2017). Contingent existence and the reduction of modality to essence. Mind, 128(509), 39-68.

Torza, A. (2015). Speaking of essence. The Philosophical Quarterly, 65(261), 754-771.

Unger, P. (1980). The problem of the many. Midwest Studies in Philosophy, 5, 411-467.

Wildman, N. (2013). Modality, sparsity, and essence. The Philosophical Quarterly, 63(253), 760-782.

Wildman, N. (2016). How (not) to be a modalist about essence. In M. Jago (Ed.), Reality making (pp. 177-196). Oxford: OUP.

Wildman, N. (2018). Against the reduction of modality to essence. Synthese, 1-17.

Wilsch, T. (2015). The nomological account of ground. Philosophical Studies, 172(12), 3293-3312.

Yablo, S. (1999). Intrinsicness. Philosophical Topics, 26(1/2), 479-505.

Zalta, E. N. (2006). Essence and modality. Mind, 115(459), 659-694.

Publisher's Note Springer Nature remains neutral with regard to jurisdictional claims in published maps and institutional affiliations. 